\title{
The Zhu Laboratory
}

\section{Department of Developmental and Molecular Biology, Albert Einstein College of Medicine, Bronx, NY, USA}

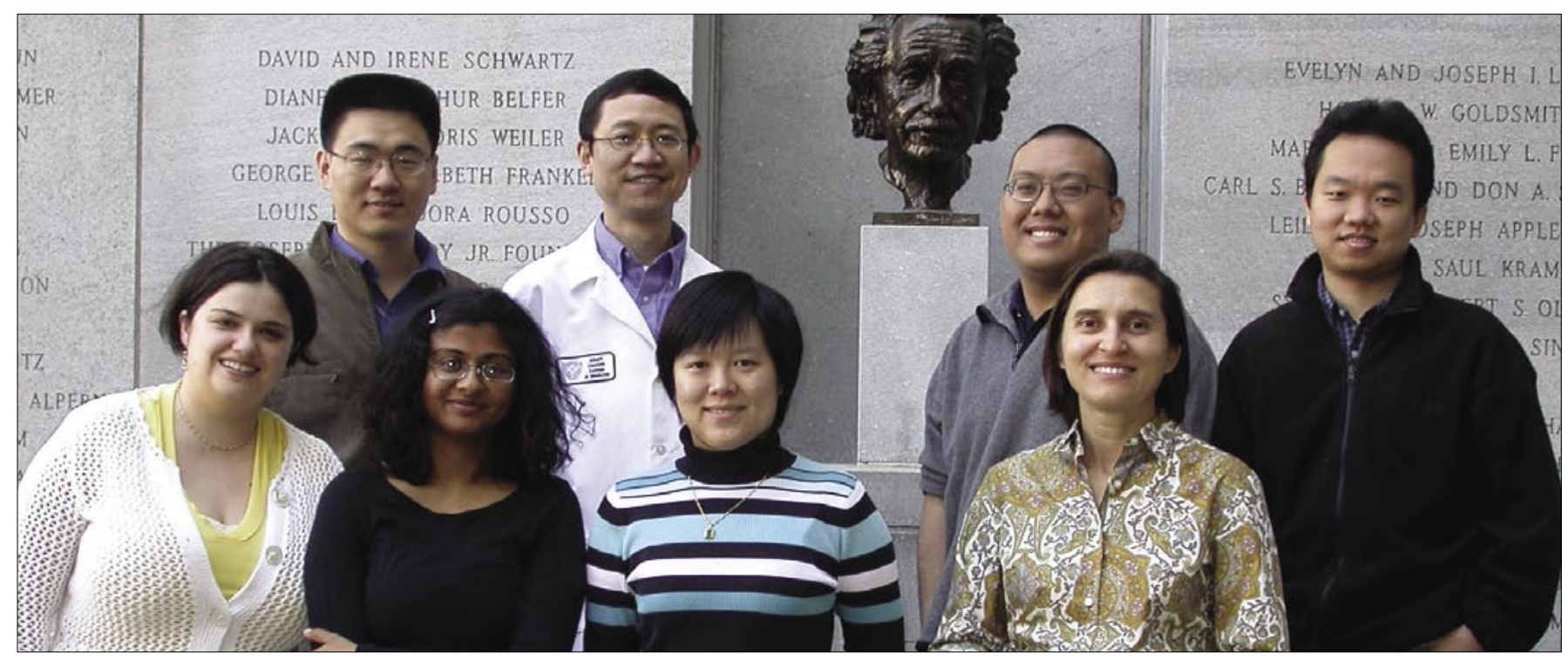

The People: Back row from left: Hongbo Wang (Graduate Student), Liang Zhu (Associate Professor), Frederick Bauzon (Graduate Student), and Peng Ji (Graduate Student). Front row from left: Luba Goldin (Graduate Student), Sunandini Sridhar (Rotation Graduate Student), Daqian Sun (Postdoctoral Research Associate), and Margherita Melegari (Rogler Lab, Postdoctoral Research Associate).

\section{The Research}

The overall goals of our lab are to understand the functional roles and mechanisms of cell cycle regulators in cancer cell proliferation and survival. We are currently focusing on the tumor suppressor $\mathrm{Rb}$, the oncoprotein Skp2, and the cyclin-dependent kinase inhibitor p27Kip1. The general importance of these regulators in cancer is demonstrated by the finding that almost all cancer cells contain abnormalities with one or more of these regulators. On the other hand, specific regulators can also play specific roles in specific types of cancer, for which we are currently focusing on the prostate cancer and liver cancer. We believe that a better understanding of how the functions of these regulators are altered in specific types of cancer cells will lead to novel targets for therapeutic intervention.

www.aecom.yu.edu/home/faculty/profile.asp?id=447

\section{The Technique}

RNA interference-based gene silencing has become an indispensable tool in laboratory research and has clear potential in therapeutic applications. A recent advance in the gene silencing field is the discovery that natural microRNA (miRNA) can be modified to silence artificially targeted genes with improved efficiency. It has remained clear however, that further improvement is needed to achieve efficient silencing of many genes when silencing constructs are present in low copy numbers in target cells. We have now established a simple and effective multi-miRNA hairpin method that significantly improves knockdown efficiencies over a corresponding singlehairpin construct. In addition, this method can be used to silence at least two genes in a linked fashion with high efficiency. We have been using this method to identify cell cycle regulators that play important roles in proliferation and survival of various cancer cells. We are also interested in applying this method to projects with direct translational potential.

Multi-miRNA hairpin method that improves gene knockdown efficiency and provides linked multi-gene knockdown, p. 59. 